\title{
Literatura, violencia y crisis. Pareceres sobre el gesto político y proléptico en la literatura ${ }^{1}$

\author{
Literature, Violence and Crisis. Opinions \\ over the Political and Proleptic Gesture in Literature
}

\author{
Sandra Navarrete Barría \\ Universidad de Santiago de Chile \\ sandra.navarrete.b@usach.cl
}

\section{Resumen}

En este ensayo propongo una lectura estética y política de la reciente narrativa chilena de ficción, con el objetivo de rastrear las distintas formas en las que esta construye vínculos con sus lectorxs, proponiendo como postulado general que es posible rastrear un trabajo por interpelar al lector, en función de que la violencia emerja como un vector de análisis válido para interpretar nuestra realidad. Me concentraré en el arco que comprende desde la posdictadura hasta nuestros días, para delimitar ciertas líneas discursivas que fracturen la normalidad impuesta por los regímenes de transición y que acerquen a lxs lectorxs al abismo de la crisis y a los distintos trayectos que recorre la violencia en nuestra cotidianeidad. ¿Cuánto de la crisis que estamos viviendo estaba ya inscrita en la narrativa reciente? ¿Cómo fue evolucionando esta inscripción?, ¿qué matices podemos distinguir?

Palabras clave: Literatura, estética, política, crisis, sociedad.

\begin{abstract}
In this essay I propose an aesthetic and political reading of the recent Chilean fiction narrative, aiming at tracing the different ways in which this narrative reaches the reader and what it does in such encounters. My general postulate proposes that in this narrative it is possible to trace a work of appealing to the reader so as to enable for the violence to emerge as a critical tool to interpret our reality. I analyze works from post-dictatorship to the present day to delimit certain discursive lines that fracture the normality imposed by the transitional regimes, and bring readers closer to the abyss of the crisis and to the different paths where violence runs through in our daily lives. How much of the crisis we are experiencing was already recorded in the recent narrative? How did this inscription evolve? What nuances can we distinguish?
\end{abstract}

Keywords: Literature, aesthetics, politics, crisis, society.

1 Este artículo se enmarca en el proyecto Fondecyt de Iniciación 11180079: "Intersecciones entre violencia y género. Hacia una estética intersticial”. ANID/CONICYT + Fondecyt, del cual soy Investigadora Responsable. 
En uno de los pocos encuentros que tuve con colegas y alumnxs, entre medio de paralizaciones generalizadas en torno a la revuelta social del pasado octubre del 2019, uno de mis más queridos amigos y colega levantó la mano para argumentar que, como académico que lleva años trabajando el tema de la violencia, se sentía profundamente interpelado con lo que estaba sucediendo en las calles. Si la tortura y represión habían vuelto - explicaba - era porque nosotros no habíamos hecho bien la pega. Me pregunté entonces y me sigo preguntando: ¿es tan alta nuestra responsabilidad social como académicxs? ¿Estaba en nuestras manos haber cambiado el camino irrevocable de la crisis social chilena desde nuestro lugar de críticxs? ¿O significa que no hemos sabido construir un sistema de vinculación con la sociedad lo suficientemente sólido como para difundir nuestras investigaciones y preocupaciones más profundas? Lo cierto es que la academia es un lugar que, si bien defiendo, me parece que al menos debe hacerse cargo de la soledad en la que trabaja, de esta burbuja ostentosa que de frágil o ligera no tiene nada, pues está revestida de duras paredes que se han esculpido a fuerza de años de especialización y toneladas de papers codificados con un lenguaje tecnicista. Es por esto que mi fe siempre ha estado más puesta en la literatura, aquella que circula libremente por los vagones del metro o que te recomienda un amigo. Y desde mi humilde trinchera siempre he procurado rescatar aquellas narrativas que hablan de la crisis y que, al modo de un prisma, multiplican e iluminan sus facetas, desde la cercanía que solo pueden construir ciertos relatos.

Cuando pienso en literatura chilena de la crisis, pienso en aquellas obras que nos cuentan los distintos modos en los que esta interviene y atraviesa las diferentes subjetividades, experiencias, afectos y pensamientos que habitan el cotidiano de cualquier chilenx y que, gracias a este mismo gesto, son capaces de interpelar a un grupo amplio de lectorxs. Durante bastante tiempo visualicé la producción literaria reciente, específicamente la narrativa, como un largo correlato de posdictadura, es decir, como obras que con distintos matices elaboraban este trauma ineludible desde varios subgéneros: crónica, autobiografía, testimonio, autoficción, novela apocalíptica, novela policial, ficciones de la memoria, entre otros. En dicha estela narrativa, me detuve en autorxs como Alejandra Costamagna, Carlos Labbé, Andrea Jeftanovic, Mauricio Electorat, Fátima Sime, Alejandro Zambra, María Eugenia Lorenzini, Alberto Fuguet, Nicolás Vidal, Lina Meruane, Ángel Saldomando, Diego Zuñiga, Cynthia Rimsky, Sara Bertrand, Leonardo Sanhueza, Nona Fernández, y por supuesto en Diamela Eltit. Hoy es claro para mí que ya no se puede pensar en esta estela narrativa solo como ecos de la dictadura que juegan estéticamente con el límite entre lo biográfico y lo ficcional, sino que hay que incluir necesariamente aquel momento en el cual como chilenxs nos fue imposible eludir la crisis, pues ya no estaba a la vuelta de la esquina de quien quisiera doblar, ahora se tornaba visible incluso para aquellos que evitan las inflexiones. Allí estaba la revuelta social y nos pilló desprevenidos.

La inclusión del estallido social en la revisión de las narrativas conlleva volver a ellas cambiando o ampliando las interrogantes y los conceptos teóricos, pero, sobre 
todo, incluyendo esta vez el ejercicio crítico de no soltar el sentipensar personal y colectivo que ha desatado esta experiencia del abismo ante la crisis, y que pasa por cuestionar todo lo establecido, desde una inusitada idea de comunidad, que es la que finalmente le otorgó fuerza al movimiento: el encuentro con el otro. Bajo este alero, me resulta interesante retomar la pregunta sobre cómo contar o representar literariamente la crisis. Para Nelly Richard, los "discursos de la crisis" no son simplemente los que hablan de ella, sino que aquellos que consiguen generar crisis en la comunidad receptora y que buscan fracturar la homogeneidad de las discursividades oficialistas. Richard propone esta reflexión a propósito de la Revista de Crítica Cultural, explicando que los discursos de la crisis eran escrituras precarias que circulaban por los márgenes y que son muy importantes de revisitar y reintencionalizar en pos de un debate cultural amplio y diverso, objetivos principales que persiguió dicho proyecto editorial (473). Los discursos de la crisis constituyeron, entonces, una respuesta a la dictadura en tiempos de difícil visibilidad y difusión del pensamiento crítico, y el rescate de estas operaciones significó un verdadero ejercicio de memoria, en tanto resignificación del pasado y práctica política que buscaba conectar el arte con la sociedad.

Sobre la base de esto, podemos afirmar que los discursos de la crisis se caracterizan por enunciarse en contextos históricos convulsionados por la violencia; promover la articulación entre artes, saberes y sociedad; rechazar textualidades autorreferenciales y eludir las verdades absolutas en pos de germinar y dispersar la interrogante por la crisis. Como se puede observar, estas discursividades nos permiten establecer diálogos con nuestro contexto actual, en donde reemerge desde el campo literario la pregunta sobre cómo enfrentar estos tiempos y qué nuevos desafíos aparecen en este horizonte. Más específicamente, me pregunto ¿cuánto de la crisis que estamos viviendo estaba ya inscrita en la literatura, desde la narrativa de posdictadura hasta la más reciente? ¿Cómo fue evolucionando esta inscripción? ¿Qué matices podemos distinguir? Y, por otro lado, ¿qué otras formas de aproximación a las narrativas me permiten abarcar diálogos críticos entre literatura y sociedad? ¿Cómo podemos eludir la inmanencia y, en definitiva, la burbuja académica? Ahora bien, cuando el grupo de la Revista de Crítica Cultural se aboca a este proyecto, no está pensando en las prácticas específicas de la literatura, sino que en un conjunto variopinto de constructos culturales erigidos desde los márgenes institucionales que acoge diversas disciplinas y formas artísticas de expresión. En función de esto, es pertinente hacer algunas acotaciones sobre las especificidades de la literatura en tanto discurso de la crisis o, en otras palabras, cuáles son las operaciones particulares que esta puede realizar en procesos sociales de transformaciones abruptas.

La política es un concepto al que hay volver para resituar la pregunta de la estética literaria en contextos de crisis, y aquí me interesan los aportes de Jacques Rancière, quien en su extensa obra ensayística se ha encargado de replantear este concepto. Para el filósofo francés, el ejercicio político emerge allí donde se producen reconfiguraciones del orden establecido que ha definido los límites de la coexistencia de un grupo 
determinado de personas. Por lo tanto, es prerrequisito del ejercicio político el que, efectivamente, "exista la configuración de una forma específica de comunidad" (15), y que esta sea intervenida con propuestas que modifiquen el orden de las cosas y reacomoden el lugar que ocupamos, cada unx como sujetos miembros de dicho orden.

La reflexión de Platón sobre quiénes pueden ejercer la política en la comunidad griega es tomada por Rancière para explicar la idea de reconfiguración. Platón explica que solo algunos sujetos pueden ejercer la vida política en la polis griega ya que esta demanda tiempo y dedicación. Es así como lxs artesanxs, por ejemplo, no gozan de esta posibilidad en tanto solo se dedican a su trabajo y no pueden acceder a la vida pública. Para Rancière, la actividad política "comienza precisamente cuando ese hecho imposible vuelve en razón, cuando esos y esas que no tienen el tiempo de hacer otra cosa que su trabajo se toman ese tiempo que no poseen para probar que sí son seres parlantes, que participan de un mundo común" (16). Entre la configuración hegemónica de la vida política griega y la reconfiguración hipotética e insumisa que postula Rancière, se encuentra el umbral del ejercicio político. Asimismo, en la frontera entre el Chile neoliberal que normaliza la precarización de las vidas y las marchas multitudinarias que se tomaron las calles, paralizando toda productividad, se reconfiguró la vida política y se reconstruyó aquello que el filósofo francés denomina como el "reparto de lo sensible", para referir aquella "distribución y redistribución de los espacios y los tiempos, de los lugares y las identidades, de la palabra y el ruido, de lo visible y lo invisible" (16).

En este marco de comprensión del fenómeno político, situamos la literatura como una de las tantas vías posibles que tienen la cultura y las comunidades de aportar a este reparto de lo sensible. Para ello hay que comenzar — siguiendo el pensamiento de Rancière- con no homologar el ejercicio político de la literatura, ni con los compromisos sociales de sus escritorxs, ni con las formas en las que estxs representan los movimientos políticos, problemáticas sociales o identidades culturales en sus obras. "La expresión 'política de la literatura' implica que la literatura hace política en tanto literatura [...] Supone que hay un lazo esencial entre la política como forma específica de la práctica colectiva y la literatura como práctica definida del arte de escribir" (Rancière 15). En este sentido, dicha particularidad implica que la literatura puede participar de la vida pública y política en tanto recorta mundos posibles desde un conjunto movedizo de objetos, temas, arengas, silencios, imágenes, espacios, los que, aunque nos trasladen a mundos futuros o fantásticos, gozan de aquello común que permite la interrelación e identificación con la sociedad que los recibe.

Dicho poder es el que me interesa rastrear en este estudio, esas distintas formas en las que la narrativa chilena construye vínculos con el otro y lo que puede hacer en dicho encuentro, proponiendo como postulado general que es posible rastrear un trabajo persistente y cambiante por interpelar a lxs lectorxs en función de que la violencia - en sus distintos matices - emerja como un vector de análisis para interpretar y actuar sobre nuestra realidad. En atención a esto, me concentraré en el arco 
que comprende desde la posdictadura hasta nuestros días para delimitar ciertas líneas discursivas que fracturen la normalidad impuesta por los regímenes de transición y que acerquen a lxs lectorxs al abismo de la crisis y a los distintos trayectos que la violencia recorre en nuestra cotidianeidad. Y aunque estos discursos narrativos de la crisis ya no se alojen en los espacios de producción marginal - $\mathrm{o}$ al menos no en su mayoría-, sino que se publiquen en un mercado editorial accesible y desechable, igualmente consiguen proponer caminos de acceso político a la comunidad y -en términos de Ranciére - una serie de reconfiguraciones de lo sensible. En función de lo anterior, me pregunto por los filtros que le permiten a la narrativa revestirse de la crisis y conectarla con la experiencia de lxs lectorxs, qué recortes de mundo realizan y qué relaciones se advierten entre estas discursividades.

La cartografía que propongo a continuación no pretende abarcar exhaustivamente un periodo de producción narrativa ni describir cada novela escogida en función de temas, espacios o personajes; tampoco busca acotar corpus de análisis independientes, sino que constituye un esfuerzo por revisitar ciertas obras ya analizadas en trabajos previos e incluir otras que deseché en su momento, para indagar en los modos en que se aborda la violencia como filtro narrativo que permite provocar el encuentro con lxs lectorxs, pero ya no como un correlato de dictadura, sino como ejercicios que encierran desde ya el desenlace de la crisis social actual. Es una cartografía que, en definitiva, propone dos formas de leer los corpus recientes, construyendo un diagrama de la violencia a partir de las siguientes variables: autorreferencialidad y lo intersticial.

\section{Lo propio y lo ajeno en la narrativa de autoficción}

\footnotetext{
“'QQué es la literatura?’ no es en absoluto una pregunta de crítico, no es en absoluto una pregunta del historiador o del sociólogo que se interroga frente a determinado hecho de lenguaje. Es en cierto modo un hueco que se abre en la literatura, un hueco donde esta tendría que alojarse y probablemente recoger todo su ser" (Foucault 73).
}

En los últimos años se ha desarrollado una profusa producción crítica y teórica en torno a la narrativa autoficcional (Amaro, Cánovas, Ternicier, Saavedra, Espinosa) que nos impide pasar por alto que existe, efectivamente, un fenómeno específico en nuestra narrativa chilena que apunta a construir personajes protagónicos que se identifican amplia, sutil o ambiguamente con lxs mismxs autorxs detrás de ellos. Rodrigo Cánovas define la particularidad de la autoficción en que "alguien cuenta su historia en primera persona y bajo su nombre propio, pero los hechos que narra no necesariamente le han sucedido" (18). Para Lorena Amaro, la autoficción se diferencia del género autobiográfico en la configuración de una pose menos seria, pues ya no 
le interesa la verosimilitud de su relato, incluso cuando se inscribe el nombre propio del autxr en la diégesis textual. Lo autoficcional permite borrar las pretensiones de verdad de la autobiografía, haciendo ecos de nuestros tiempos de posmodernidad, ironía y desconfianza en las certezas metafísicas. De esta forma, sintetiza: "el concepto de autoficción corresponde a aquella narración en que el nombre del autor es igual al del narrador y personaje principal, pero sin embargo el pacto de la lectura no es autobiográfico, sino novelesco" (273). En esta misma sintonía, son escrituras que se conectan con el recurso metaficcional y proponen juguetonamente a sus lectorxs distintas puestas en abismo. Algunas de las novelas que se reconocen bajo este alero son Formas de volver a casa, La vida privada de los árboles y Bonsái de Alejandro Zambra, Sangre en el ojo de Lina Meruane, Camanchaca de Diego Zúñiga, No ficción y Missing de Alberto Fuguet, American Visa de Marcelo Rioseco, Allegados y Casa propia de Ernesto Garrat, entre varias más.

Una de las características que más se discute sobre este tipo de novelas es la autorreferencialidad con la que lxs narradorxs se exponen a sí mismxs, y con ello, en el juego de la autoficción, son lxs mismxs autorxs y sus vidas quienes salen a colación en los análisis, entrevistas y estudios. Si bien, y como ya hemos constatado, a diferencia de las autobiografías estas narrativas no buscan una historia verdadera y abarcadora de la vida de lxs autorxs, igualmente, la referencialidad de estas anécdotas, antecedentes y experiencias del autxr que se cuelan en el relato ficcional y epitextual pasan a formar parte del campo literario. Estas pequeñas pistas que van sugiriendo realidad y que tienen como punto centrípeto la vida de un solo individuo, es entendido por Patricia Espinosa como una respuesta colectiva a las condiciones de un neoliberalismo imperante y egoísta, apuntando que "estas narrativas se proyectan como espacios de saturación del yo, en términos de primacía autorreferencial” (69). En este sentido, y justamente a partir de la idea de respuesta colectiva a una crisis social —observada desde el neoliberalismo- es que propongo leer estas autoficciones como uno de los lugares más políticos de la narrativa reciente.

Estas narrativas muestran la experiencia cotidiana de la violencia del sistema en la rutina, en sus procesos escriturales, en lo íntimo de la vida en pareja, desde una perspectiva narratorial única que, no obstante, busca instalarse en un campo literario cada vez más heterogéneo y dinámico, y todos los elementos que intervienen en él determinan la forma en la que lxs autorxs se presentan al mundo. Aún más allá, podemos decir que "todo escritor, no solo piensa su obra en relación a los otros escritores, sino que también se instala y se muestra, se emblematiza y debate, en el espectro y la claridad que las otras vidas y las otras escrituras, le posibilitan" (Chababo 38). De esta forma, no es menor que existan numerosas novelas autoficcionales circulando, al contrario, esto permite y delinea una reconfiguración de lo sensible y, por lo tanto, un ejercicio político que posibilita a mi juicio el que estxs escritorxs dibujen —aunque sea en su cruce con lo ficcional- sus propios contornos identitarios, abriendo una puerta concreta hacia un diálogo con el otro. A continuación, analizaré dos autoficciones 
- Bonsái de Alejandro Zambra y Sangre en el ojo de Lina Meruane- para observar cómo se filtra la violencia y cómo este filtro cuestiona la posibilidad de un encuentro con el otro en la sociedad actual.

Bonsái de Alejandro Zambra, publicada en el año 2006, ha sido leída como una novela que se pregunta sobre lo que es la literatura, a través de ciertos recursos como la alegoría, la parodia y la metaficción. También como una novela que muestra el desencanto social mediante dos jóvenes universitarixs sin proyectos ni éxito alguno, que terminan uno como profesor particular que vive en un piso subterráneo y la otra lanzándose a las vías del metro en Madrid. Para Noemi Voionmaa, la novela de Zambra instaura la narrativa de lo mínimo, aludiendo a aquellos recursos y usos específicos del lenguaje que se alejan del exceso, la codificación o el adorno y buscan, en cambio, lo simple. Este rasgo se une con lo metaficcional en tanto el relato mínimo evidencia el andamiaje que conlleva la construcción de un texto. En la lectura que propongo, quiero destacar otra dirección de lo mínimo en Bonsái que tiene que ver con la construcción especular de la autorreferencia persistente que invoca a lxs lectorxs a hacerse ciertas preguntas y mirar por esta rendija una sociedad en donde reina la supremacía del yo, pero, además, el predominio de la especialización. De este modo, emerge un recordatorio constante de que la novela desechará todo aquello que se aleje de la historia de Emilia y Julio, porque esta es la historia que se contará y lo demás no importa. "En este relato la madre de Anita y Anita, no importan, son personajes secundarios" (Zambra 47), no son relevantes tampoco los expololos de Emilia, así como tampoco Gazmuri importa, "el que importa es Julio" (63). Pero no son importantes no solo porque la novela quiera exponer la puesta en abismo del ejercicio que conlleva escribir una historia, sino que también con el objeto de develar esa sutil violencia que permea nuestras prácticas y que pasa por el afán de poner cotos a nuestras verdades y a nuestras vidas, cotos que finalmente nos alejan de los otros.

Cuando el narrador describe la relación entre Emilia y Julio, sintetiza: "Esta es la historia de dos estudiantes aficionados a la verdad, a dispersar frases que parecen verdaderas, a fumar cigarros eternos, y a encerrarse en la violenta complacencia de los que se creen mejores, más puros que el resto, que ese grupo inmenso y despreciable que se llama el resto" (Zambra 25-26). El pequeño bonsái se constituye así - no solo como una alegoría del ejercicio escritural de la novela - sino también como una metáfora de la autorreferencia y de la especialización, ambas prácticas profundamente interconectadas y que inundan las formas de relacionarnos en nuestra época. La autorreferencia se despliega desde el momento en que Julio decide cuidar un bonsái $\mathrm{y}$, al mismo tiempo, escribir una novela, relatando ambos procedimientos mientras al mismo tiempo se relata a sí mismo. La especialización, por su parte, tiene que ver con un gesto transversal en la novela que se caracteriza por construir pequeños espacios de confort y seguridad para el protagonista. Estos lugares - una relación romántica e intensa, la lectura de un libro, la escritura de una novela - permiten que Julio habite pequeños y transitorios atajos a la soledad. 
La novela Sangre en el ojo de Lina Meruane, publicada en el 2012, es la historia de Lucina Meruane, una periodista abocada a la ficción, escritora y estudiante de un Ph. D. en Nueva York que comienza a quedarse irremediablemente ciega. En la fiel compañía de su novio Ignacio y en las intermitentes apariciones de otros madre, padre, hermanxs, amigxs, doctorxs-, la ceguera arremete en cada rincón de su vida, desarmando sus rutinas y transformándola a ella misma en otra. Esta novela ha sido ampliamente estudiada en su cruce autofictivo con la posmemoria (Espinosa, Velayos, Fallas), en tanto obra que reinventa los caminos del recuerdo social al incluir esas otras voces más alejadas del núcleo duro de la violencia dictatorial y realizar una reflexión sobre lo que significa seguir rememorando en estos tiempos: la alegoría de la mirada ciega y de la memoria de los ojos va en esa línea. Por otro lado, la novela de Meruane, como señala Teresa Fallas, "es una autopsia de Chile donde los bandos político-ideológicos continúan con sangre en el ojo, porque las políticas de perdón y olvido y la amnesia oficial dejaron en la impunidad los crímenes y las desapariciones de miles de chilenos" (1). De esta forma, la protagonista describe su ojo como un ojo que tiene "litros de rencor" (Meruane 15). Lo transnacional aparece como recurso para crear zonas de contacto especular con la realidad chilena, así, la descripción del subway gringo o de la crisis económica argentina, aún en sus detalles más específicos, constituyen imágenes que observamos en nuestro país y que hoy cobran más sentido que nunca: la pobreza que conmueve, la desesperanza de la gente.

Los pensamientos de Lina ocupan la mayor densidad narrativa del texto, se puede observar desde las primeras líneas cómo tanto el diálogo con los demás como la misma acción del relato se ralentizan en pos de darle cabida y protagonismo a la voz de su conciencia. Esto me recordó una de las relaciones que le permiten a Foucault reflexionar sobre la locura como metáfora de la ajenidad de la literatura. Para el filósofo, la posibilidad de hablar y la de estar locos en nuestra sociedad son formas muy similares de intervenir en el mundo: "Tengo la impresión [...] de que abren, bajo nuestros pies, la más peligrosa pero acaso también la más maravillosa o la más insistente de nuestras libertades" (53). En este sentido, mi interpretación del gesto autoficcional de la novela de Meruane se concentra en el desarrollo de esta capacidad parlante de la protagonista, que crece a medida que aumenta su ceguera. Esta enfermedad, que poco a poco la va separando de los círculos sociales, hasta reducirla casi exclusivamente a su relación con Ignacio, es la que le otorga la oportunidad de dar rienda suelta a sus pensamientos, a través del lenguaje. Este lenguaje enfermo, en conjunto con la identidad de Lina/Lucina/Luciferina, se contorsiona oscilante entre pasividad y acción, entre victimización y agencia, para finalmente, y luego de enterarse de la irreversibilidad de la ceguera, dar paso a su nueva identidad.

Ahora bien, la libertad de hablar que le confiere la enfermedad se desarrolla en la diégesis, en tanto discurrir del pensamiento de Linia, pero gracias al gesto autoficcional y a señales como las conversaciones con Silvina, su tutora de tesis, observamos 
que esa voz mental se torna escritura: “Tú solo puedes ser tú en la proximidad de la palabra escrita” (Meruane 83), le dice Silvina. Es tanto el afán de la narradora por administrar este espacio propio constituido por su subjetividad que, para concentrar su relato en ella misma, y en ausencia de Ignacio, una vez instalada en el avión que la llevaría directo a Chile, divide a la protagonista en dos, armando un diálogo entre Lina al borde de un ataque de pánico y Lucina, que convulsionaba de nervios. Este recurso del desdoblamiento se repite en varias instancias y con otros personajes para reforzar la idea de lo propio y lo ajeno. Así, por ejemplo, divide a su madre en solo "su madre" y la "médica": "Estábamos las tres enredadas en el cordón de la enfermedad, inmersas las tres en un fluido pegajoso y amniótico que amenazaba con ahogarnos" (Meruane 147). La madre es aquella que se sacaría los ojos para donárselos, la médica es la que cree que no se los merece porque no los cuidaría, no obstante las tres coexisten a pesar de todo.

La problemática de la especialización que aparecía en Bonsái como una metáfora tímida, emerge aquí directamente ligado al área del saber, con ejemplos desde la medicina, la oftalmología y la teoría literaria. Es así como la madre y el padre de Lina son médicxs y desde pequeña fue testigo de aquella agotadora práctica del lenguaje codificado. Incluso es la misma madre quien prolifera la siguiente frase: "Estos médicos están tan especializados que no entienden nada de lo que sucede en el resto del cuerpo. Nada más que el órgano que estudian” (Meruane 120), para alentar a su hija ante un pronóstico del oculista que excedía la zona del ojo, que era el de una posible escasez de fierro en la sangre. En la misma línea, la narradora se aventura en echar una mirada crítica a la academia literaria, a la que ella misma pertenecía. La especialización - reflexiona- ha permitido fenómenos tan paradójicos como el del estudiar al otro - subordinado, sometido- desde diferentes teorías y no sentir empatía alguna por este otro. “Teorizar las estrategias de los sometidos y la resistencia del margen era una cosa y otra radicalmente opuesta era empatizar. La estrategia de mis colegas resultó ser esta. Hacer la vista gorda. Escudarse en sus lecturas. Protegerse en la academia y dejarse embetunar por su jerga" (Meruane 154). Lo interesante es que relaciona este gesto abstracto con el hecho concreto de que sus colegas se alejaran de ella al enterarse de su enfermedad, qué podían decirle - piensa- si solo sabían hablar de teorías.

En suma, estas novelas abordan desde distintas aristas el difícil encuentro con el otro, situando el abismo de la crisis justo en la frontera entre un "nosotrxs" y el "resto", entre un "yo" y un "tú". Estas narrativas parecen decirnos que cuesta tanto constituirse como sujetos en la época contemporánea que, en dicho esfuerzo - que nos toma la vida entera - terminamos alejando al otro, abusando del otro, utilizando al otro y, en definitiva, poniendo barreras entre mi espacio y el del resto. 


\title{
Los intersticios de la violencia contemporánea
}

\author{
"Si seguimos ignorando las palabras que nos envían ese mensaje, si los \\ medios no reproducen esas imágenes, si esas vidas permanecen innom- \\ brables y sin lamentar, si no aparecen en su precariedad y en su destruc- \\ ción, no seremos conmovidos. Nunca recuperaremos ese sentido de la \\ indignación moral por el Otro, en nombre del Otro" (Butler 187).
}

Dentro de las variadas formas narrativas que han ido apareciendo en el último tiempo y que, a diferencia de las autoficciones o las posmemorias, no gozan de un corpus teórico crítico muy amplio, distinguimos un pequeño grupo de obras emergentes que trabajan la violencia y que tienen varias características que nos permiten abordarlas bajo una misma intuición o sospecha: son novelas que están buscando nuevos modos de interpretar y acercar a lxs lectorxs las distintas crisis que habitan nuestro país. Entre las particularidades de estas narrativas podemos destacar que priorizan la construcción de sujetos precarios en atención, sobre todo a la clase social. Del mismo modo, la configuración espacial alude a la vulnerabilidad de la vida, tejiendo como puntos interconectados sujeto y espacio. Por otro lado, el tiempo narrado es el de un Chile neoliberal endeudado y empobrecido, corrupto y violento, pero que no afecta a un sujeto específico que no ha encontrado su camino, como muestra hasta cierto punto la autoficción, sino que arremete contra un grupo humano marcado desde su nacimiento por sus condiciones sociales. Si bien este grupo de narrativas no se puede emparentar con algún subgénero específico, como por ejemplo se podría pensar en una vuelta del realismo social, sí podemos apreciar ciertas zonas comunes con la crónica periodística, el realismo de la narrativa marginal —al estilo de El Río de Gómez Morel-, el género policial, entre otras. Algunas de las novelas que sitúo en este corpus son Allegados y Casa propia de Ernesto Garratt, Racimo de Diego Zuñiga, Quiltras de Arelis Uribe, Fuerzas especiales, Impuesto a la carne y Sumar de Diamela Eltit, Gol de oro de Nibaldo Acero y Qué vergüenza de Paulina Flores, entre otras.

Se podría sospechar que la violencia se filtra en estas narrativas a través de un gran panorama contextual contemporáneo que le otorga primacía al hecho violento, pero lo cierto es que los grandes paradigmas epistémicos por medio de los cuales se han pensado las relaciones entre literatura y violencia, aquí se desarman: ya no existe una sola víctima ni un solo victimario, ni se plantea un momento o periodo violento central que marque un correlato de sus efectos en los personajes, como en las novelas de dictadura. Por otro lado, no se construye un crimen o delito exclusivo que funcione como modulación principal de la violencia, como sucede en la novela negra o policial, así como tampoco se observan motivos monocausales o explicativos del acto violento, simplemente no hay detonantes específicos, la violencia está allí desde siempre. Y este es un aspecto fundamental para entender 
las propuestas de estos corpus: el sistema es el que se propone como generador y reproductor constante de la violencia.

Si abordamos este asunto desde Žižek, en estas narrativas se desecharía la violencia subjetiva para privilegiar la sistémica. Por violencia subjetiva el autor entiende aquella que es directamente visible y practicada por un agente fácilmente identificable, como por ejemplo el crimen, el terrorismo, los disturbios civiles, entre otros. La violencia sistémica sería, en cambio, aquellas consecuencias del funcionamiento coordinado de nuestras economías y nuestras políticas capitalistas. "Esta violencia ya no es atribuible a los individuos concretos y a sus 'malvadas' intenciones, sino que es puramente 'objetiva’, sistémica, anónima” (23), y estaría regida por una lógica espectral, abstracta e inexorable. Esto que Žižek llama espectral es lo que en este ensayo denomino como lo intersticial, para referirme específicamente a una estética que se preocupa de fracturar estas operaciones de ocultamiento y simplificación del horizonte de la violencia social, interconectando y materializando varias aristas a un mismo fenómeno.

La novela Racimo de Diego Zúñiga tiene como protagonista a Torres Leiva, un fotógrafo de periódico que es enviado a cubrir el extraño fenómeno de la virgen que llora lágrimas de sangre en la Iglesia de Pozo Almonte. Una vez allí, Torres Leiva se desvía de su motivación original, entregándose de lleno a investigar sobre la seguidilla de asesinatos de mujeres y niñas acaecidos en Alto Hospicio, comuna de Iquique. Esta zona es descrita como atravesada por la marginalidad y el olvido, al enclavarse en la inmensidad de la pampa desértica del norte de Chile. La narración destaca la sucesión de crímenes, pero también la pobreza y vulnerabilidad general del sector. Los acontecimientos de la novela se inspiran en hechos reales ocurrido entre 1998 y 2000, que el autor se encargó de investigar para darle un trasfondo archivístico a la historia, pero sin rendirle tributo al hecho policial del caso. Es así como la narración propone, más que una búsqueda frenética por los responsables, una investigación insegura de certeza y que se obsesiona, justamente, con estos intersticios de la violencia que se le revelan en el camino. Como muy bien lo explica Fermín Rodríguez en atención al propio título de la novela, esta no haría más que "producir con los escombros de la historia agrupamientos de sentido, constelaciones giratorias de relatos anónimos de violencia y represión cargados de un sentido ominoso que la novela se abstiene de explicar" (45). De esta forma, el narrador va afinando una mirada intersticial que se detiene en distintas escenas que son "fotografiadas" por la narración: un incendio ocurrido en un barrio de cités, "lleno de inmigrantes, las casas de madera y esos edificios de adobe en los que viven todos hacinados" (Zúñiga 85); un grupo de mujeres fuera del hospital que "llevan colgadas en sus cuellos las fotos en blanco y negro de las niñas" (75); o incluso hechos pasados, como las tomas de los terrenos donde vivían las niñas desaparecidas o el incendio que en 1986 destruyó una fábrica y calcinó a 29 obreros en 1986.

El relato de la novela muestra cómo las elecciones de Torres Leiva, que se pueden calificar como antojadizas, oscilantes o movidas por el deseo, más que profesionales, progresivas u objetivas, son las que, no obstante, le permiten acceder a uno de los 
intersticios más horrorosos y crueles que se pudiera descubrir: la prostitución infantil obligada y trata de personas en la frontera con Perú. "Se instalan, finalmente, en un living grande donde hay un escenario rodeado de sillones en los que se besan distintas parejas, mientras dos niñas bailan en un caño, dos niñas que tienen los ojos desorbitados" (Zúñiga 187). Todo esto se tiñe de una irrealidad brumosa en tanto el protagonista no recuerda cómo se fue de ese lugar ni su ubicación exacta, solo que quedaba en Tacna. Esa realidad espectral de la que habla Žižek es lo que, precisamente, esta novela consigue permear y transmitir a lxs lectorxs como operación, no tanto de desencanto como de impotencia ante la crueldad de lo descubierto: estas redes de prostitución infantil estaban tan protegidas que eran imposibles de disolver. Esta impotencia ante la vastedad del mal no se apacigua en Torres Leiva ni siquiera cuando se descubre al culpable del secuestro y violación de Ximena, un taxista clandestino. De este modo, la narración prefiere dejar abierta la sospecha sobre la interconexión de todos los elementos presentados y anular la clásica solución del crimen y la captura del delincuente como desenlace obligado.

La novela Fuerzas especiales de Diamela Eltit cuenta los modos en que la vida de una joven mujer se restringe al vaivén entre el departamento del "bloque", ${ }^{2}$ espacio en el que vive junto a su madre, padre y hermana, y el cibercafé, lugar en donde trabaja "bajándose los calzones" junto a sus colegas, Omar y Lucho. Este ambiente es constantemente asediado por las fuerzas especiales, las que inundan de violencia y temor a estas víctimas conformando una frontera sitiada por vehículos blindados y armas en constante alerta. Los "pacos" son también quienes se han llevado a sus hermanos y que se terminarán llevando a su padre. La narración en general constituye un esfuerzo discursivo por simbolizar dicho miedo tatuado en el cuerpo mismo de la protagonista, pero también en el de todos los habitantes de los bloques, que es el miedo que signa los modos de habitar el mundo de algunas personas.

A pesar de que la novela construye una suerte de escenario bélico de la violencia, en donde los allanamientos a las casas son pan de cada día y la resistencia igualmente se hace presente, no podemos decir que se trate de una estética de la violencia subjetiva - en términos de Žižek-, ya que es una violencia sin comienzo ni fin, en donde no se entienden las razones del por qué las fuerzas especiales detienen y golpean a lxs habitantes de los bloques, ni menos las causas del vuelo continuo de helicópteros para vigilar el sitio. Incluso en aquellas descripciones en las que la violencia se hace más visible, y se habla de golpes, patadas y otros, la focalización cambia con un gesto final en el que se filtran esas otras formas menos evidentes pero más constantes de ejercer violencia, como lo es la prostitución obligada, marcando allí un punto de inflexión imposible de sumar tan fácilmente a lo demás:

2 En Chile se le llama "bloques" a las construcciones habitacionales que agrupan a un conjunto de personas organizadas en edificios de tres o cuatro pisos, con pequeños departamentos para cada familia. Los "bloques" emergen como parte del Programa Vivienda Básica, impulsado por el Estado, y con el objetivo de la erradicación progresiva de los campamentos ilegales. 
Cuando detecto ese movimiento, sé que estoy sentada encima del lulo de un tira, sé que no me va a pagar, sé que si reclamo o si lo miro duramente podría sacar su pistola y matarme, sé que me pegaría un puñete en la boca, sé que me tiraría del pelo, sé que me daría una patada en el estómago, sé que trataría de sacarme un ojo, sé que he perdido media hora de trabajo y trecientos pesos. Qué haré, me pregunto, ahora que las rondas se intensifican si solo entran pacos y tiras a mi cubículo. O qué haremos el Lucho, el Omar y yo si se les produce una necesidad obsesiva, abajo, en sus lulos, mientras dan vueltas y vueltas para inmovilizar a los bloques (Eltit 126-127).

Las mujeres y los cuerpos feminizados son los que más sufren violencia, ya que es una ofensa doble que se posibilita en tanto mujeres pobres. En ese sentido, estos cuerpos, si bien son individuales, se reflejan como espejos que refractan imágenes iguales, constituyendo cada una un espectro de la otra. Esto lo alegoriza Eltit en la figura del cuerpo gordo: "Pero nuestra gordura, provocada siempre por infames circunstancias, era necesaria porque así nos parecíamos como mujeres y sabíamos que ese exceso, esa grasa y esa precisa azúcar nos iba a proteger ante los pacos y los tiras pues nos volvíamos indistinguibles" (56).

Ambas novelas se proponen el tratamiento estético de la violencia contra sujetos vulnerables y precarizados que están siendo sistemáticamente asediados por diferentes fuerzas de opresión, sumisión y abuso. Judith Butler propone que existirían "formas de distribución de la vulnerabilidad" (14) que serían los modos de repartir diferenciadamente la violencia en las sociedades, de acuerdo a "marcos interpretativos" predominantes en el discurso de una comunidad, que relegan a ciertos sectores de la población hacia espacios de total exposición; como en estos casos, Alto Hospicio y los bloques, que se interpretan fácilmente como cualquier población chilena con alto grado de narcotráfico que es "intervenida" por la policía. En estos contextos, y siguiendo a Butler, el dolor que generan ciertas muertes versus la indiferencia y anulación de otras es lo que evidencia estas diferencias: "La distribución diferencial del dolor que decide qué clase de sujeto merece un duelo y qué clase de sujeto no, produce y mantiene ciertas concepciones excluyentes de quién es normativamente humano. ¿Qué cuenta como vida vivible y lamentable?” (16-17).

Basándose en esto, Butler postula que constantemente funcionan distintos mecanismos para negar la existencia de los sujetos vulnerables, de modo tal que, luego de su muerte, estos no sean llorados. Dos de estos mecanismos serían el "duelo" y la "desrealización del otro", el primero se refiere a la indiferencia sistemática sobre el dolor y la muerte de sujetos precarios, y el segundo a las formas en que la vida de estos mismos sujetos es negada continuamente. "La desrealización del otro quiere decir que no está ni vivo ni muerto, sino en una interminable condición de espectro" (60). En el caso de Racimo, lo espectral abre la novela con la figura de una niña de cabello largo, vestida de uniforme, haciendo dedo en la orilla de la carretera. Imagen icónica de las 
niñas violadas y asesinadas por el psicópata de Alto Hospicio, crímenes que el narrador denuncia como carentes de un duelo dignificador. Mientras que en Fuerzas Especiales la poética de Eltit se encarga de minimizar las diferencias entre los cuerpos, los que a su vez se funden con los bloques, también iguales entre sí. Ambos mecanismos están íntimamente relacionados: en la medida que los sujetos precarios son desrealizados, carecerán de duelo y sus vidas no serán lloradas ni validadas. De este modo, para entender la violencia desde la teoría del sujeto precario de Butler hay que ir más allá del crimen o del acto violento en sí. Como punto de partida, esta autora propone analizar aquellos marcos que nos hacen reconocer al "otro" como potencial víctima en la medida que es un sujeto precario, cuya vida es poco importante o de plano negada y, por lo tanto, no merece dolor ni duelo. Dentro de este marco de reconocimiento del "otro" la violencia desmedida contra ellxs resulta algo natural y escasamente cuestionado.

En suma, el murmullo de lo intersticial se constituye como otra forma de interpretación de la violencia, que es aquella que ya no tiene cómo desenredarse en sus distintas aristas, pero la que tampoco es posible visibilizar fácilmente. Es decir, goza de una fuerte estructura y soporte sistémica, pero dicho soporte está entramado subrepticiamente, en un espacio de difícil acceso que le otorga características cercanas a lo etéreo. De esta forma, la literatura que muestra la violencia intersticial queda en una encrucijada entre representatividad realista y espectralidad marginal, entre estéticas que, por un lado, denuncian la crueldad, y por otro, construyen personajes escasamente audibles.

\section{Conclusiones}

"El bloque, el mío particularmente, el que yo habito, es una representación del bloque miedo, una forma gráfica que podría levantarse, hincharse, inflarse cualquier día y explotar como un tubo de gas porque la presión del miedo llegaría a niveles inmanejables y el estallido sería la única forma de consumación" (Eltit, 89).

La revuelta social pensada como una explosión, es decir, como una liberación brusca de energía que se produjo desde nuestros lugares privados hacia las calles, y adquirió forma y sentido en la marcha colectiva, destaca la pregunta por los desplazamientos de dichas energías desde la coronacrisis. ¿Hacia dónde se mueven y qué dinámicas están desarrollando esas energías? Esta metáfora física pensada desde mi confinamiento obligado me lleva a visualizar ineludiblemente las políticas públicas de cuarentena como una implosión, es decir, como el proceso inverso a la explosión, en el cual la energía se libera hacia adentro. Visto así, la implosión se sitúa como el modo más conveniente de acallar ese gran ruido que significó el estallido y convertirlo en algo así como un crunch, aquel sonido que oímos cuando masticamos, pero que escasamente se escucha en el exterior de nuestras bocas. 
Ante este panorama añadido, me pregunto qué le queda a la literatura cuando las mismas subjetividades que ya estaban en crisis - como lo hemos desarrollado a partir de las autoficciones - se están viendo profundamente transformadas a partir de la experiencia pandémica. Este es un asunto no menor y que ya está siendo reflexionado por varias figuras intelectuales, entre las que destaco a Paul B. Preciado:

Lo que se habrá inventado después de la crisis es una nueva utopía de la comunidad inmune y una nueva forma de control del cuerpo. El sujeto del technopatriarcado neoliberal que la Covid-19 fabrica no tiene piel, es intocable, no tiene manos. No intercambia bienes físicos, ni toca monedas, paga con tarjeta de crédito. No tiene labios, no tiene lengua. No habla en directo, deja un mensaje de voz. No se reúne ni se colectiviza. Es radicalmente individuo. No tiene rostro, tiene máscara (párr. 24).

Un escenario como este se plantea como una prolongación del silencio que estamos viviendo en la actualidad y es justamente este silencio el que se aprecia en muchas narrativas chilenas, sobre todo en las ficciones de la memoria y posmemoria, en las que el trauma heredado fue lo que generó implosiones en las subjetividades. El silencio también se configura en las estéticas de lo mínimo y las prácticas de la especialización, como vimos en las narrativas autoficcionales, no obstante, aquí la autonarración puede llegar a constituirse como gesto político que permite ciertas reconfiguraciones de lo sensible, a partir de la nunca inocente apropiación de la palabra. Por otro lado, el silencio muchas veces se constituye también como un intersticio infranqueable que todo lo abarca y ante el que, aunque nos rebelemos mediante la denuncia, no se conseguirá nada. Es el silencio de la impunidad, de la corrupción a gran escala, de la violencia sistémica. Es la censura, el colapso de una estructura que todos percibíamos como insostenible, pero que nadie se atrevía a acusar firmemente, es la sombra a la que se le permitió seguir creciendo.

En suma, y volviendo al concepto de "discursos de la crisis" postulado al comienzo de este ensayo, y a la pregunta sobre cómo enfrentar desde la literatura las fracturas del sistema y las esperanzas ahora silenciosas que dejó la revuelta del pasado octubre, considero que a la luz de lo que ha significado este ejercicio lector, conviene detenerse y considerar al menos dos aspectos principales: en primer lugar, el camino de lo colectivo y comunitario es lo que permite que nuestras narrativas crunch explosionen en las calles, pero no solo como forma esperanzadora, sino que también como ejercicio político que denuncia la violencia, que seguramente se seguirá filtrando por los intersticios de nuestra sociedad. En segundo lugar, es importante construir vías alternativas de articulación de los saberes, a los que se accede de manera tan compartimentada hoy en día. Si bien este es uno de los objetivos que buscaron los discursos críticos en la dictadura, finalmente, terminaban circulando igual en otras burbujas especializadas, por lo tanto, es tiempo de repensar la idea de margen/institución a la luz de las nuevas formas de comunicación y de relaciones que se están imponiendo hoy en día. Por 
último, pensar la crisis desde ahora implica una postura crítica obligada: nunca más soltar la crisis, hacerla asomar en aquellos lugares en donde se ha ocultado, hacerla audible allí donde se ha silenciado y multiplicar sus interpretaciones, de modo que siempre exista el diálogo.

\section{Referencias}

Amaro, Lorena. La pose autobiográfica. Ensayos de narrativa chilena. Santiago de Chile, Ediciones Universidad Alberto Hurtado, 2018.

Butler, Judith. Vida precaria: el poder del duelo y la violencia. Buenos Aires, Paidós, 2006.

Cánovas, Rodrigo. Escenas autobiográficas chilenas. Santiago de Chile, Ediciones UC, 2019.

Chababo, Rubén. “Saer: la imagen del escritor". Revista de Letras. Discusión, Suplemento de Crítica Literaria, n. ${ }^{\circ}$ 1, 1989, pp. 37-44.

Eltit, Diamela. Fuerzas especiales. Santiago de Chile, Seix Barral, 2013.

Espinosa, Patricia. "Política de la posmemoria en la narrativa chilena". Bonsái, n. ${ }^{2}$ 24, 2019, pp. 65-82.

Fallas, Teresa. "Sangre en el ojo: víctima y victimaria encarnadas en una misma persona”. Bonsái, n. ${ }^{\circ} 29,2014$, pp. 1-24.

Foucault, Michel. La gran extranjera: para pensar la literatura. Buenos Aires, Siglo XXI, 2015.

Meruane, Lina. Sangre en el ojo. Santiago de Chile, Random House Mondadori, 2012.

Noemi Voionmaa, Daniel. "Formas de volver a la memoria. El minimalismo de Alejandro Zambra”. Revista Nuestra América, n. ${ }^{\circ} 10,2016$, pp. 49-62.

Preciado, Paul. "Aprendiendo del virus". El País, 28 de marzo de 2020, https://elpais. com/elpais/2020/03/27/opinion/1585316952_026489.html

Rancière, Jacques. Política de la literatura. Buenos Aires, Libros del Zorzal, 2011.

Richard, Nelly. "En torno a la 'Revista de Crítica Cultural"'. Revista de Estudios Hispánicos, n. ${ }^{\circ} 22,1995$, pp. 471-480.

Rodríguez, Fermín A. "Cuerpo y capitalismo: el trabajo de la violencia y el miedo". Estrategias. Psicoanálisis y Salud Mental, n. ${ }^{\circ}$ 4, 2016, pp. 43-46.

Velayos Amo, Beatriz. "Estancia en las fronteras del género: autoficción y posmemoria en Sangre en el ojo de Lina Meruane". Impossibilia. Revista Internacional de Estudios Literarios, n. ${ }^{\circ}$ 14, 2017, pp. 168-186.

Zambra, Alejandro. Bonsái. Barcelona, Anagrama, 2006.

Žižek, Slajov. Sobre la violencia. Seis reflexiones marginales. Buenos Aires, Paidós, 2009.

Zuñiga, Diego. Racimo. Santiago de Chile, Literatura Random House, 2014.

Enviado: $1^{\circ}$ de septiembre de 2020

Aceptado: 20 de diciembre de 2020 